\title{
CHALLENGES OF AIR FORCE TRANSFORMATION
}

Jew security challenges and advances in technology—sensors, communications 1 and information technologies in particular-impact the way militaries around the world are organized and equipped to perform their roles. Our expectation is that, rather than leading to one-step reorganization and restructuring of the military, these factors will bring permanent adaptation, designated recently as transformation.

To reflect the impact of these developments on air forces and related organizations, the Editorial Board of Information \& Security: An International Journal (I\&S), jointly with the AFCEA-Varna Chapter and the Headquarters of the Bulgarian Air Force, initiated the preparation of this special I\&S issue.

Air Force transformation was the overarching theme of the AFCEA conference on "The Bulgarian Air Force - Missions and Roles in the Context of National and Collective Security," organized by the AFCEA-Varna Chapter ${ }^{1}$ and conducted under the auspices of the Bulgarian Minister of Defense in Plovdiv, Bulgaria. Part of the articles in this volume is based on selected presentations made at this conference.

New roles, missions and tasks of the Air Force, expected to be performed in variety of conditions, form the reference point of transformation. Air Forces are preparing to deal with ill-defined asymmetric threats, under uncertain scenarios in multi-agency and multinational setting. In addition, very often Air Forces are expected to assist civilian authorities in law enforcement, search and rescue, and environmental tasks.

To do that effectively, Air Forces shall be able to act in a network-centric manner, where net-centricity is achieved through very high degree of connectivity, near realtime situational awareness, distribution of decision-making authority, and a range of flexible capabilities. Such features are in the process of institutionalization through development of novel doctrine and tactics, adequate organization, and insertion of advanced technologies.

In addition, technological opportunities allow for lower number of personnel, however with more diverse skills and better trained. Therefore, transformation places a special emphasis on continuous education, e-learning, and qualitative improvements in individual, crew, and staff training. 
The focus of this issue, however, is on the technological modernization of the Bulgarian Air Force. The first part looks at the overarching challenges of transforming the Bulgarian Air Force and the respective requirements, priorities, plans and programs for acquisition of new weapon systems, equipment, command and control, communications, radars, and navigation systems, presented by Lieutenant General Simeon Simeonov, Commander of the Air Force. This part includes also assessment of the challenges faced by the Bulgarian Air Force from the perspective of NATO, as well as description of current U.K practices in procurement for the air force that may facilitate innovative thinking in the search for higher efficiency in spending limited investment budgets.

Not surprisingly, the focus of attention is on the expected acquisition of new multirole fighters. The second part of the issue provides detailed requirements and examples how this acquisition can (and should) be approached. It starts with elaboration on the role of airpower and the possible definition of air force Mission Capability Packages that would provide for wide spectrum of out-of-area operations and operations on the territory — and airspace — of the country. The final two articles treat exclusively the problem of procuring multipurpose fighters, primarily from operational analysis perspective. As usual, this volume contains useful information on online and other resources of interest to the discourse on air force transformation.

In order to succeed, Air Force transformation needs a clear vision, supported by adequate concepts, doctrine, policies, and technology acquisition. The reader will not find answers to all related questions in this issue. We believe, though, that this I\&S volume will provide novel ideas, analysis of experience, and description of advanced technological opportunities, that will be found useful not only in conceptualizing transformation of air forces but also in more tangible ways as regards planning, program and project management, and implementation of advance operational analysis techniques.

Information \& Security

${ }^{1}$ Additional information on the activities of the AFCEA-Varna Chapter the reader may find at www.afcea.bg. 